\title{
FUNÇÃO SOCIAL DA EMPRESA DE TELECOMUNICAÇÃO E A PRESTAÇÃO DE SERVIÇOS NA RELAÇÃO DE CONSUMO DE TELE ATENDIMENTO
}

\author{
Alessandra Harumi Sakai dos Santos ${ }^{1}$, Carla Bonomo ${ }^{2}$, Pedro Teófilo de Sá ${ }^{3}$ \\ ${ }^{1}$ Universidade do Oeste Paulista - UNOESTE. Curso de Administração, Presidente Prudente - SP. ${ }^{2}$ Universidade \\ Estadual de Londrina - UEL. Curso de Direito, Londrina - PR. ${ }^{3}$ Universidade do Oeste Paulista - UNOESTE. Curso de \\ Direito, Presidente Prudente -SP. E-mail: makoto2004@hotmail.com
}

\section{RESUMO}

O objetivo deste artigo é analisar a proatividade do administrador na aplicação da função social da empresa de telecomunicação na relação de consumo decorrente dos serviços tele atendimento. Estudar-se-á a importância da Função Social no século atual no serviço de tele atendimento na empresa de telecomunicação e a ação proativa do administrador orientado pelo Código de Defesa do Consumidor. Com as mutações na seara empresarial, esta tem que se adequar à realidade de consumo do presente século, em relação ao serviço de tele atendimento e a relação de consumo, de modo que a proatividade do gestor apresenta-se fundamental na prestação dos serviços de tele atendimento. Desta forma, a organização manterá o equilíbrio na relação consumo, cumprindo, assim, a função social. As evidências disponíveis demonstram que a predisposição proativa do administrador é fator determinante para a aplicação da função social da empresa de telecomunicação, na relação de consumo no tele atendimento.

Palavras-chave: Função social, tele atendimento, telecomunicação e relação de consumo.

\section{SOCIAL FUNCTION OF TELECOMMUNICATIONS COMPANY AND THE PROVISION OF SERVICES IN RELATION TO CONSUMPTION OF TELE SERVICE}

\begin{abstract}
The purpose of this article is to analyze the proactivity of the application administrator in the social role of telecommunications company in the ratio of consumption resulting from teleassistance services. Will be to study the importance of Social Function in the present century in the tele-assistance service company in telecommunications and proactive administrator action guided by the Code of Consumer Protection. With the changes in the business harvest, this has to fit the reality of consumption of this century, compared to the tele-assistance service and the ratio of consumption so that the proactive manager presents fundamental in the provision of tele services care. Thus, the organization will maintain a balance in consumption ratio, thus fulfilling the social function. The available evidence shows that proactive predisposition administrator is decisive for the application of the social function of the telecommunications company in the ratio of consumption in tele service factor.
\end{abstract}

Keywords: social function, tele service, telecommunications and consumer relationship. 


\section{INTRODUÇÃO E OBJETIVO}

A função social tem sido destaque na atualidade, tornando-se mais importante do que os próprios bens materiais, devido à exigência de rupturas de paradigmas e fatos concretos, inclusive mudanças na prestação de serviços. Antigamente as empresas visavam uma otimização dos resultados econômicos, mas, modernamente observa-se uma mudança de mentalidade organizacional, imposta por meio de leis que visam proteger o consumidor de sua vulnerabilidade e hipossuficiência. Cabe lembrar que, o código de defesa do consumidor surgiu para assegurar o equilíbrio da relação consumerista nas organizações. Por isso, a postura proativa do administrador também configura um dos requisitos fundamentais para a resolução de problemas que norteiam as organizações.

A globalização e as mutações do ambiente empresarial demandam das organizações uma nova forma de operacionalização de suas ações, especialmente no que diz respeito ao tele atendimento. Nessa relação de consumo a lei consumerista estabelece que o consumidor $^{1}$ é considerado vulnerável, o que justifica que o Estado intervenha nas relações de consumo, coibindo práticas abusivas contra o consumidor, para equilibrar a relação de consumo, em respeito a dignidade humana.

Pautado nessa realidade, o objetivo do presente trabalho consiste em analisar a proatividade do administrador na aplicação da função social da empresa de telecomunicação na relação de consumo decorrente dos serviços tele atendimento.

\section{METODOLOGIA}

A pesquisa cientifica deve ser composta por procedimentos sistemáticos, e conforme Rampazzo, (2005, p. 73) “a metodologia explica o tipo de pesquisa, se é bibliográfica ou documental [...]". O termo metodologia pode indicar também o referencial teórico, ou quadro de referência. O presente trabalho apresenta uma abordagem qualitativa, e tem como instrumento de coleta de dados para a sua realização, a pesquisa bibliográfica através de livros, artigos científicos, revistas especializadas e sites jurídicos.

\section{RESULTADOS}

As evidências disponíveis demonstram que, na relação de consumo do serviço de tele atendimento na telecomunicação, a empresa está inserida numa nova realidade legal, fato que desencadeia a necessidade da aplicação da função social, conexa com o desenvolvimento da

\footnotetext{
${ }^{1}$ Pessoa física ou jurídica que adquire ou utiliza produtos ou serviços como destinatário final. O consumidor é aquele subordinado às condições e interesses impostos pelo titular dos bens ou serviços no atendimento a suas necessidades de consumo. CF art. $2^{\circ}$ do CDC. 
lucratividade e à manutenção do bem-estar da coletividade. Esse fenômeno é dependente da proatividade do administrador em busca da detecção e resolução de problemas, sem perda do foco social e da lucratividade. Para que isso corra, diante dos serviços de tele atendimento nas empresas de telecomunicação deve haver o respeito aos direitos básicos do consumidor, garantidos pelo código consumerista.

\section{DISCUSSÃO}

Para entender a função social da empresa de telecomunicação na relação de consumo decorrente dos serviços tele atendimento, é necessária uma abordagem teórica sobre a comunicação e a informação na relação de consumo.

A comunicação é fundamental para o ser humano, e para a convivência em sociedade, já que os fatos humanos orbitam as várias formas de comunicação.

Para demostrar essa nova realidade, Corrêa (2006, p.247) demonstra que:

"[...] o surgimento de uma sociedade mais individualizada, profundamente diferente da chamada "sociedade de massas" e que se caracterizava pela produção e distribuição em massa de bens e serviços altamente padronizados para o homem médio, como público alvo dos fabricantes da grande maioria de produtos. A esta imagem se contrapõe uma sociedade que passou de uma base industrial para a base da informação. A partir disso, a produção em massa cede lugar à diversificação, para mercados cada vez mais bem informados e segmentados."

Observa-se, que a informação é a principal ferramenta da nova era, os próprios receptores exigem uma comunicação que gere informações claras e dinâmicas. Salienta-se que a empresa deve ser eficaz na prática das suas ações, atenta para o fato de que os clientes procuram as que melhor satisfaçam suas necessidades, tendo em vista a concorrência e a busca por clientes. Então, a organização, "Para ter sucesso, deve ser flexível, adaptativa e eficiente. Deve ter processos decisórios ágeis que lhe permitam identificar tendências e gerar soluções com oportunidade. " (OLIVEIRA, 2009, p. 5)

Por esta forma de atuação a empresa precisa de um gestor deve ter ações proativas, demonstrando flexibilidade e precisão nas suas ações, em busca da manutenção no mercado. Na empresa de telecomunicação, no tele atendimento o administrador deve agir de forma proativa, estando precavido acerca de ocorrências danosas à empresa e ao cliente, a fim de preservar a relação de consumo.

Atendimento é a chave principal em uma empresa de telecomunicação, e deve visar atingir a máxima satisfação do cliente, o que, contribuirá para o marketing positivo. "[...] pode-se dizer que o atendimento tem que "fazer das tripas, coração" para servir os interesses do cliente, ganhar 
a sua confiança e criar as oportunidades para poder opinar e para orientar na adoção do melhor caminho. " (CORRÊA, 2006, p. 49)

Observa-se que o cliente deve ser bem atendido, principalmente quando diz respeito ao serviço de telecomunicação, uma vez que se trata de serviço por meio de mídia, ou seja, sem contato pessoal com o consumidor.

Modernamente o administrador do seguimento de telecomunicação deve agir cautelosamente, adotando uma postura proativa ${ }^{2}$, visando minimizar a aflição do consumidor pela busca da solução do problema, quando é acionado o serviço de tele atendimento, já que os contatos virtuais, realizados por telefonia eletrônica facilitam a prestação de serviços valendo-se de meios midiáticos de informação.

O século XXI exige das empresas uma postura estratégica e eficiente que gere maior satisfação e funcionalidade dos serviços no atendimento, orientados na ampla interconectividade através das evoluções das telecomunicações e as diversificações da comunicação, sempre entrelaçada com a função social. Tal assertiva encontra fundamento também, nos artigos 116, parágrafo único e 154, da Lei das Sociedades Anônimas ${ }^{3}$ (LSA), abaixo transcrito, (BRASIL, Presidência da República, 1976):

Art. 116. Parágrafo único. O acionista controlador deve usar o poder com o fim de fazer a companhia realizar o seu objeto e cumprir sua função social, e tem deveres e responsabilidades para com os demais acionistas da empresa, os que nela trabalham e para com a comunidade em que atua, cujos direitos e interesses deve lealmente respeitar e atender.

Art. 154. O administrador deve exercer as atribuições que a lei e o estatuto lhe conferem para lograr os fins e no interesse da companhia, satisfeitas as exigências do bem público e da função social da empresa.

É importante notar que a função social da empresa, constante até mesmo na lei das Sociedades Anônimas, mostra-se fundamental para limitar algumas ações do empresário, na busca valorização do ser humano, e não somente na pretensão de riquezas materiais a qualquer custo. Assim, é possível concluir, a função social advém da Constituição Federal e lei das Sociedades Anônimas. Por isso, a organização deve trilhar um caminho de mão dupla ao desenvolver a atividade empresarial pautada pretensão lucrativa e na execução da função social.

As decisões do administrador devem sempre estar voltadas para o bem comum, como forma de executar a função social. Para Teles (s.d.) o princípio da função social inspira a preservação da empresa e determina a continuidade da atividade empresarial, com respeito à

\footnotetext{
${ }^{2}$ Prever uma situação e agir antes dela acontecer, estar atento a sua volta, ter raciocínio rápido, ter ação.

${ }^{3}$ Lei $^{\circ} 6.404 / 76$
} 
relação de consumo. Tal respeito demonstra o importante papel social da organização, dentre eles a geração de emprego, como forma de execução da dignidade humana e o bem-estar coletivo que, hodiernamente é uma exigência para a sobrevivência no mercado, além do respeito à lei priorizando-se os direitos humanos.

Almeida (2003, p. 141) afirma: “A Função Social da empresa deve ser entendida como o respeito aos direitos e interesses dos que se situam em torno da empresa". Sendo assim, quando o gestor atua com ética e com respeito aos direitos do consumidor, estará exercendo a função social.

Nesse contexto, o gestor deve agir cautelosamente ao lidar com a diversidade de pessoas no serviço de tele atendimento, pois as pessoas atendidas não possuem qualquer tipo de controle ou conhecimento sobre os serviços prestados. É primordial a adoção de políticas empresariais e treinamentos contínuos de seus colaboradores.

Conforme Oliveira (2003, p. 326)

Acompanhar o dinamismo do mundo contemporâneo exige um esforço muito grande das pessoas e, em especial dos profissionais ou executivos. A eles não é mais permitido serem lentos e medíocres, pois necessitam mostrar-se capazes e decidirem rápida e seguramente.

A sociedade contemporânea tem feito da vida das pessoas uma luta sem fim, e a cada dia as pessoas necessitam estar melhor do que foram, atualizadas, por dentro do que acontece e aptas a antever os cenários futuros.

Nas organizações, a linguagem que predomina é a mudança continuada, o aperfeiçoamento constante, encontrar oportunidades independentemente da situação, se favorável ou não. É o momento em que se fala em prosperar no caos, achar espaços que possam suplantar qualquer tipo de dificuldade.

Observa-se que nesse novo cenário a organização deve adequar-se á nova realidade, pois, os clientes estão cada vez mais exigentes. É nesse momento que se observa a conectividade da proatividade do gestor com a relação de consumo na prestação de serviço de tele atendimento, solucionando problemas antes que se agravem. É necessário abandonar a postura meramente reativa e ingressar na esfera da proatividade, sendo capaz de ir além do que usualmente as organizações fazem.

"A sociedade atual exige, do administrador consciente, uma postura inovadora e proativa ante as situações-problema". (AÇÕES..., 2009, p. 22-23)

Tal postura fará toda a diferença, levando à solução do problema. Ser proativo, portanto, é sobrepujar os obstáculos corrigindo, a todo tempo, toda e qualquer circunstância que venha desrespeitar a função social da empresa de telecomunicação, no tele atendimento. A atitude 
proativa poderá manter equilibrada a relação de consumo, em atendimento ao respeito ao consumidor.

O mundo global de grandes avanços e descobertas, marcado pela evolução das telecomunicações e surgimento de uma forte competição, está nascendo e forçando as organizações e as pessoas a assumirem novas posturas, diferentes de tudo aquilo que até então foi válido. [...] Hoje em dia, pressionado pela situação adversa, prevalece um novo tipo de relacionamento em que todos são considerados parceiros, tomando parte no negócio e buscando soluções que sejam boas para ambas as partes. (OLIVEIRA, 2003, p. 327)

A futuridade das decisões é de extrema importância, tanto que o mesmo autor enfatiza que o progresso que está eclodindo ao redor das organizações tem exigido atitude diferenciada para que haja reciproco benefício entre as partes interessadas (stackholders).

"Essa mudança afetou significativamente a forma de relacionamento da empresa, mudando especialmente seu comportamento ético, privilegiando comportamentos mais condizentes com valores morais de respeito, consideração, fidelidade, sinceridade e amizade, contrariando, assim, os valores que prevaleceram no passado, quando o certo era levar vantagem em tudo: cada indivíduo ou organização queria aproveitar ao máximo seu poder e se beneficiar das fraquezas dos seus opositores, pois era dessa forma que os parceiros de hoje eram considerados. (OLIVEIRA, 2003, p. 328)"

Considerando o raciocínio exposto, a valorização do ser humano vem sendo cada vez mais requisitada em virtude desta mutação. Por isso, as empresas de telecomunicação devem estar atentas a esta alteração, que poderá comprometer além da sua reputação, a relação de consumo.

Huisman (apud TROPE, 1999) sustenta que hoje em dia há uma mudança de paradigmas, a racionalidade instrumental $^{4}$ está sendo complementada ou até mesmo substituída pela racionalidade substantiva ${ }^{5}$. A organização tradicional utiliza a racionalidade instrumental porque privilegia o aspecto econômico, pois, movidos pelo mercado criam exigências próprias não coincidindo com o que é requerido pela boa qualidade da existência humana. Na sociedade atual a racionalidade substantiva vem sendo crescentemente utilizada, pois está desacoplado das possibilidades de sucesso, o que privilegia a consciência e a preocupação com a ética.

Nessa esteira, entende-se que uma nova racionalidade é exigida no século atual, aquela que visa em primeiro lugar atender as necessidades humanas pautadas na ética e nos princípios morais, deixando em segundo plano o sucesso empresarial que, para existir, deve atender de forma coerente às exigências do consumidor de modo a preservar a relação de consumo e o respeito ao ser humano.

\footnotetext{
${ }^{4}$ Refere-se a qualquer meio adequado para atingir um determinado fim.

${ }^{5}$ Preocupa-se com a ética para atingir determinado fim. 
O mercado de trabalho fala muito no perfil de um profissional polivalente, ou seja, aquele profissional que possa dar conta de várias situações do dia a dia da empresa. [..] Na realidade, as empresas buscam um profissional que possa resolver problemas, pois este parece ser o grande requisito do mercado. (OLIVEIRA, 2003, p. 342)

O profissional com essas qualidades é muito requisitado, e as empresas de telecomunicação em busca de agilidade, solução e maximização de resultados almejam pessoas com ações diferenciadas. Mas para isso, elas devem ser treinadas para oferecer um serviço pautado na função social e o respeito ao código consumerista.

Oliveira (2003, p. 350) esclarece que:

[...] o profissional polivalente é aquele que possui uma visão mais ampla, que não fragmenta seus diferentes saberes, que não departamentaliza os problemas da empresa ou, traduzindo em miúdos, que possui uma visão sistêmica. Esse profissional deve ainda compartilhar sua visão com os membros da equipe e demais colaboradores da empresa, pois de nada adianta ter vasto conhecimento, uma visão ampla sobre mercado, produto, serviços, etc., se tudo estiver apenas em sua memória. Se assim correr, esse profissional nunca poderá sair de férias, e a empresa se vê dependente do cérebro dele. [...] o profissional polivalente é aquele que se adapta perfeitamente ao meio em que paira o pensamento sistêmico, a visão compartilhada e passa a ter um modelo mental que o impulsiona para o desenvolvimento de suas competências. E, para tanto, que possa utilizar todas as suas competências (espectro de competência = inteligência) para resolver os múltiplos problemas que surgem constantemente no ambiente de uma empresa.

É possível concluir que a organização moderna necessita de profissionais, fato que não é diferente na área de telecomunicação, no tele atendimento, já que a prestação de serviço não deve ser robotizada, ou seja, o profissional deverá conhecer todos os aspectos legais, bem como a política da empresa e suas limitações, para que ofereça o melhor serviço a fim de garantir aos prestadores de serviço a solução dos problemas. A competência é um dos requisitos que garantem a efetivação de um trabalho com excelência e eficiente para fazer cumprir as obrigações e a função social da empresa, sem perder o foco legal consumerista.

\section{CONSIDERAÇÕES FINAIS}

A visão da complexidade das relações existentes na sociedade, e da comunicação permanente entre indivíduos propicia uma nova postura administrativa frente aos serviços de tele atendimento, visando agregar competências, demandadas para a plena atuação no serviço de telecomunicação. Tal atitude deverá ser seleta, e a comunicação e a informação deverão ter um alto desempenho para que possa ser atendida a função social da empresa, para, harmonicamente, reger a relação de consumo do serviço de telecomunicação, no tele atendimento. 
Diante das evidencias literárias, a postura tanto do administrador como do prestador de serviço deve ser proativa, para que a função social da empresa de tele atendimento do serviço de telecomunicação seja cumprida. Com isso, as ações do administrador devem ser cautelosas, uma vez que o código de defesa do consumidor protege o consumidor, a parte mais fraca na relação de consumo.

Então para que haja função social implícita na organização o Administrador deverá ir além de suas ações, independente da exigência da lei, pautado numa conduta moral e ética, não somente visando crescimento econômico da organização, mas atendendo a relação de consumo de forma a valorizar o consumidor. É preciso ter em primeiro plano o melhor atendimento solucionando problemas de forma rápida, satisfazendo os anseios do cliente. O código consumerista tem como objetivo manter o equilíbrio entre as partes de maneira favorecendo a ambos. E ainda, ampara o consumidor por ser vulnerável e hipossuficiente contra os abusos do fornecedor, que tem o dever de oferecer a informação referente ao produto ou serviço ofertado, atendendo o consumidor de forma a satisfazer suas necessidades.

Com base nesses enunciados, pode-se inferir a necessidade de adquirir o conhecimento através da informação para haver comunicação eficiente na organização, levando informação correta no tempo certo e de maneira assertiva.

Por fim, para entender o objeto maior deste estudo, a função social da empresa de telecomunicação no tele atendimento, conclui-se que o gestor deve ter ação proativa contínua, voltado para o bem estar social, em busca da finalidade almejada pela organização. O exercício da função social no serviço de tele atendimento é uma conduta de extrema importância nos dias atuais, já que garante a valorização do ser humano diante de uma adversidade de situações, em estrito respeito ao código consumerista.

\section{REFERÊNCIAS}

Ações premiadas no $13^{\circ}$ concurso Inovação na Gestão Pública Federal. Brasília: ENAP, 2009. Disponível em:<http://www.enap.gov.br/downloads/livro_14_concurso.pdf>. Acesso em: 12 Jun. 2014.

ALMEIDA, M. C. A Função Social da empresa na sociedade contemporânea: perspectivas e prospectivas. ARGUMENTUM - Revista de Direito - Universidade de Marília, v. 3 - Marília, v. 3, 2003. Disponível em: <http://www.unimar.br/biblioteca/publicacoes/direito/Direito_vol_03.pdf>Acesso em: 08 ago. 2014 
BRASIL. Congresso Nacional. Presidência da República Casa Civil. Lei n 6.404, de 15 de dezembro de 1976. Dispõe sobre as Sociedades por Ações. Diário Oficial da União, Brasilia, DF, 15 dez. 1976. Disponível em:

<www.planalto.gov.br/ccivil 03/leis/16404consol.htm> Acesso em: 17 jun. de 2014.

CORRÊA, A. O atendimento na agência de comunicação. São Paulo: Global, 2006.

OLIVEIRA, A. B. S. Controladoria: fundamentos do controle empresarial. São Paulo: Saraiva, 2009.

OLIVEIRA, J. F. TIC: Tecnologias da Informação e da Comunicação. São Paulo: Érica, 2003.

RAMPAZZO, L. Metodologia Cientifica: para alunos dos cursos de graduação e pos- graduação. 2. ed. São Paulo: Edições Loyola, 2004.

TELES, G. F. S. A função social da empresa. Disponível em: < http://blog.newtonpaiva.br/direito/wp-content/uploads/2012/08/PDF-D13-03.pdf> Acesso em: 08 ago. 2014.

TROPE, A. Organização virtual: impactos do teletrabalho nas organizações. Rio de Janeiro: Qualitymark, 1999. 